\title{
Is psychodynamic psychotherapy an effective intervention for individuals at ultra-high risk (UHR) of psychosis? A case report
}

\author{
É a psicoterapia psicodinâmica uma intervenção eficaz para \\ indivíduos em risco ultra-alto (UHR) de psicose? Um relato de caso
}

Paula A. Martins', Priscila Dib Gonçalves ${ }^{1,2}$, Silvia Maria Arcuri ${ }^{1,3,4}$, Oswaldo F. Leite Netto ${ }^{3}$, Gamaliel Macedo', Mario Louzã'

\begin{abstract}
Objective: To report a case and to discuss the use of psychodynamic psychotherapy (PDP) to treat individuals at ultra-high risk (UHR) of psychosis. Methods: An individual at UHR was followed up for 24 months. The baseline evaluation included a psychiatric interview, the Structured Interview for Prodromal Symptoms (SIPS), the Scale of Prodromal Symptoms (SOPS), and neuropsychological assessment. He underwent weekly sessions of PD-P for 12 months and was followed up for 12 months after the end of PD-P. The evaluations were at baseline, after 6-, 12-, and 24-month follow-up. No medication was prescribed during the 24-month follow-up. Results: The prodromal symptoms remitted. The initial total score on the SIPS/SOPS was 37 points. After the first 12 months of PD-P, there was a reduction to 12 points on the SIPS/SOPS score, which stabilized in the 24-month follow-up. There was also a slight improvement in his performance on the neuropsychological evaluations. Conclusion: This case report suggests that PD-P can reduce prodromal symptoms; nevertheless, a better understanding of the specificity and efficacy of PD-P as an option of treatment for UHR individuals is needed.
\end{abstract}

\section{RESUMO}

Objetivo: Relatar um caso e discutir o uso da psicoterapia psicodinâmica (PD-P) no tratamento de indivíduos com risco ultra-alto (UHR) para psicose. Métodos: Um indivíduo UHR foi acompanhado por 24 meses. A avaliação inicial incluiu entrevista psiquiátrica, aplicação de instrumentos padronizados, Entrevista Estruturada Para Sintomas Prodrômicos (SIPS), a Escala de Sintomas Prodrômicos (SOPS) e avaliação neuropsicológica. O indivíduo teve sessões semanais de PD-P durante os primeiros 12 meses e continuou acompanhamento durante os 12 meses seguintes após o término da PD-P. Avaliações foram feitas no início do estudo e após 6, 12 e 24 meses de seguimento. Nenhuma medicação foi prescrita durante todo o seguimento. Resultados: Os sintomas prodrômicos remitiram. Apresentou, ainda, discreta

1 University of Sao Paulo Medical School (FMUSP), Institute of Psychiatry (IPq), Early Psychosis Evaluation and Intervention Program (ASAS), Sao Paulo, SP, Brazil. 


\author{
Palavras-chave \\ Psicose, risco ultra-alto \\ (UHR), psicoterapia \\ psicodinâmica.
}

melhora no desempenho nas avaliações neuropsicológicas. Conclusão: Este relato sugere que a PD-P pode reduzir os sintomas prodrômicos, no entanto uma melhor compreensão da especificidade e eficácia da PD-P como uma opção de tratamento para os indivíduos UHR é necessária.

\section{INTRODUCTION}

One of the most significant current discussions in psychiatry is the potential beneficial aspects of early intervention in psychosis. The detection and early intervention aims to reduce delays in starting treatment, and to minimize the deterioration of the condition. Attempts have been made worldwide to identify individuals at ultra-high risk (UHR) to develop psychosis over the last 15 years?

The term UHR is utilized to characterize a "mental state" that precedes the onset of psychosis. There are three UHR syndromes: a) brief limited intermittent psychotic symptoms, b) attenuated positive psychotic symptoms, c) genetic risk associated with recent decline in social functioning ${ }^{2}$.

Many early intervention programs have been developed focusing on treatment and research of these subjects ${ }^{3}$. Moreover, there is growing evidence on the positive impact of early psychosis intervention ${ }^{4,5}$. One of the most used instruments to evaluate and diagnose UHR subjects is the Structured Interview for Prodromal Syndromes (SIPS). It consists of a structured interview, and also includes the Scale of Prodromal Symptoms (SOPS) that measures the severity of prodromal symptoms, a family history questionnaire, the Schizotypal Personality Disorder Checklist, and the Global Assessment of Function (GAF) ${ }^{6}$.

Pharmacological and nonpharmacological interventions have been studied to evaluate their potential in delaying or even preventing the onset of a full-blown psychosis. Among the nonpharmacological interventions to treat UHR subjects, the Cognitive Behavior Therapy (CBT) has been extensively investigated and its benefits remain unclear as some studies demonstrated to successfully delay the onset of full-blown psychosis at its early prodromal stages and other studies do not show any differences in comparison with placebo ${ }^{7-9}$.

The primary focus of psychodynamic psychotherapy (PD$P$ ) is to reveal the unconscious content of a client's psyche in an effort to alleviate psychic tension. It also relies on the interpersonal relationship between the client and the therapist, focusing on interpretations of transference, defense mechanisms, current symptoms, and the working of unconscious conflicts. Free association is used as a major method for investigation of internal conflicts ${ }^{10}$.

The effectiveness of PD-P as a tool for the treatment of severe mental disorders has been investigated in recent sys- tematic reviews and meta-analysis. These have shown that long-term (at least 1 year) PD-P is effective in the treatment of complex mental disorders, including personality disorders, multiple and chronic disorders, with an effect size of about 1.8 ${ }^{11}$. When compared with less-intense psychotherapies, long-term PD-P was more effective, with an effect size of 0.44-0.68 ${ }^{12}$. However, there has been little discussion about the effectiveness of PD-P in individuals at UHR.

We report a case and discuss the possibility of using PD-P as a nonpharmacological intervention in subjects with UHR for psychosis.

\section{Case report}

Mr. A, male, 22 years sought our early intervention program (ASAS, Institute of Psychiatry (IPq), University of Sao Paulo, Brazil) with his parents due to changes in behavior, difficulties in his studies, social withdrawal, and suspiciousness. He took a train to nowhere, missed several college exams, and "disappeared" for a few hours without informing his parents. He was the only child, had a normal neuropsychomotor development, had no learning or motor disabilities during his childhood, and appeared to be a child without any "problem". However, at around 12 years, his parents noticed that nothing seemed to please him. He started spending a long time alone in his bedroom, didn't make new friends, and was always alone. This change in this behavior was attributed to adolescence by his parents.

He was evaluated at baseline with the Structured Interview for Prodromal Symptoms (SIPS), clinical laboratory and neuropsychological assessment at baseline, and 6-, 12-, and 24-month follow-up. He underwent weekly sessions of PD-P and was clinically evaluated every 3 months. No medication was prescribed during the 24-month follow-up.

He went to PD-P once a week for 12 months. Mr. A had individual sessions with a senior psychotherapist (SMA) at IPq under supervision by a psychoanalyst (OFLN) of the Brazilian Society of Psychoanalysis of São Paulo (SBPSP). Thorough psychiatric and neuropsychological evaluations and ratings with the Scale of Prodromal Symptoms (SOPS) occurred after 6 months and 12 months of follow-up; at these moments, he had attended 20 and 36 sessions, respectively. After the end of the PD-P, he was followed up for 12 months, and a thorough evaluation was completed 24 months after baseline. 
At baseline assessment, the patient reported difficulties in social relations and communication. He had in the SOPS a total score of 37 and the Global Assessment of Functioning (GAF) was 71. He fulfilled criteria for UHR (attenuated positive symptoms and schizotypal personality disorder). The neuropsychological assessment showed average cognitive performance, with mild impairments in long-term visual memory (Table 1). From the psychodynamic perspective, low selfesteem, excessive attachment, and dependency on parental figures were observed.

After 6 months of PD-P, he showed difficulties in social communication and in his relationships, mainly with his parents. A change in the focus of report from everyday activities to his internal world, feelings, thoughts, was observed.

We observed an important reduction in the scores of the SOPS (Table 2) and he was able to return to college and began to work as a trainee. During the PD-P sessions, Mr. A could gradually express his feelings and thoughts, being able to overcome the period of complaints about others. He showed conflicts in his emotional development; at the same time, an infantile and dependent relationship with parental figures and movements was observed in the direction of consolidating a mature self.

Despite the fact that he still presented attachment and dependency on parental figures, especially his mother with whom he had a relationship with permeable boundaries,
Mr. A began to have insight on his repetitive patterns of functioning and progressed to more independent decisions in his life. After about 12 months of PD-P, he was promoted in his job to a new position, which included more responsibilities and the management of a team.

In his last evaluation (12 months after the end of PD-P), Mr. A reported going out with friends more often; he also wanted to leave his job in 6 months and study abroad for 1 month. He still expressed some difficulties with social relations and "fights" for independence from parental control.

His SOPS was stable with scores comparable to the 12-month evaluation (Table 2). Comparing the neuropsychological assessments, we observed an improvement in sustained attention, processing speed and basic attentional processes, and executive functions.

Table 2. Psychiatric evaluations (SIPS and SOPS) at baseline and follow- up

\begin{tabular}{lcccc}
\hline & Baseline SIPS & $\begin{array}{c}\text { 6-Month } \\
\text { Follow up SOPS }\end{array}$ & $\begin{array}{c}\text { 12-Month } \\
\text { Follow up SOPS }\end{array}$ & $\begin{array}{c}\text { 24-Month } \\
\text { Follow up SOPS }\end{array}$ \\
\hline Positive Sx & 7 & 5 & 2 & 1 \\
Negative Sx & 15 & 8 & 7 & 6 \\
Disorganized Sx & 6 & 3 & 1 & 1 \\
General Sx & 9 & 5 & 2 & 5 \\
Total score & 37 & 21 & 12 & 13 \\
\hline
\end{tabular}

SIPS: Structured Interview for Prodromal Symptoms; SOPS: Scale of Prodromal Symptoms; SX: symptoms.

Table 1. Neuropsychological evaluation at baseline, 6 months follow up and 12-months follow-up

\begin{tabular}{|c|c|c|c|}
\hline Neuropsychological tests & Baseline & 6-month follow up & 12-month follow up \\
\hline \multicolumn{4}{|l|}{ Trail Making Test (TMT) } \\
\hline Part A & Borderline & Average & Average \\
\hline Part B & Average & Average & High Average \\
\hline \multicolumn{4}{|l|}{ Stroop Color Word Test (SCWT) } \\
\hline Part I & Borderline & Low Average & Average \\
\hline Part II & Average & Low Average & Average \\
\hline Part III & Average & Average & Average \\
\hline Controlled Oral Word Association Test (COWAT) & Average & Average & Average \\
\hline \multicolumn{4}{|l|}{ The Rey-0sterrieth } \\
\hline Complex Figure Test (ROCFT) & Superior & Superior & Average \\
\hline Forward Digits (WMS-III) & Very Superior & Very Superior & Very Superior \\
\hline Backward Digits (WMS-III) & High Average & Average & Superior \\
\hline \multicolumn{4}{|l|}{ Wisconsin Card Sorting Test (WCST) } \\
\hline Categories Completed & Average & High Average & Very Superior \\
\hline Perseverative Errors & Average & Average & Superior \\
\hline Failure to maintain set & High Average & Low Average & Average \\
\hline Logical Memory I(WMS-III) & Average & Average & High Average \\
\hline Logical Memory II (WMS-III) & High Average & High Average & High Average \\
\hline Faces I(WMS-III) & Average & Average & Superior \\
\hline Faces II (WMS-III) & Low Average & Average & Superior \\
\hline Verbal IQ (WASI) & Superior & High average & Superior \\
\hline Performance IQ(WASI) & Average & Average & Average \\
\hline Total IQ (WASI) & Average & Average & Average \\
\hline
\end{tabular}

1Q: intelligence quotient; WMS-III: Wechsler Memory Scale - Third Edition; WASI: Wechsler Abbreviated Scale of Intelligence.

Results are shown according to the normative data (from the worst to the best cognitive functioning): Very Poor, Borderline, Low Average, Average, High Average, Superior, and Very Superior. 
The subject gave us informed consent and agreed that his case could be reported in a scientific journal. We took all measures to avoid publishing information that could allow someone to recognize the identity of the patient.

\section{DISCUSSION}

The literature on the use of PD-P in UHR subjects is scarce. Juckel et al. ${ }^{10}$ published a book about this subject where they discuss the understanding of the prodromal phase from a psychodynamic point of view, emphasizing the difficulties these subjects have with relationships and the progressive dissolution of their self.

Uzdawinis et al. ${ }^{13}$ used the Operationalized Psychodynamic Diagnostics (OPD) to evaluate 20 UHR subjects and compared them to 10 patients with schizophrenia. They concluded that the UHR subjects were in a more favorable condition to PD-P, showing a less-aversive interaction with partners and investigators in comparison with patients with schizophrenia. They also classified UHR subjects in "far from psychosis" and "close to psychosis" and showed that the "far from psychosis" subjects were less impaired in their intensity of conflicts of self-esteem and integration in "defense" and "attachment." They conclude that the use of the OPD could complement the psychiatric evaluation and help in the indication of PD-P.

Even though we did not use the OPD, similar psychodynamic characteristics were expressed by our patient before the begging of PD-P.

Some new psychoanalytical concepts such as "attachment" and "mentalization" describe failures in infantile relationships that lead to severe impairments in adult relationships, even to personality disorders ${ }^{14}$.

Using the theoretical framework of Melanie Klein ${ }^{15}$, he shifted from a schizoparanoid to a depressive position. In the beginning of the PD-P process, he was experiencing paranoid anxiety, splitting of objects (all "good" or all "bad"). Along the PD-P, the development feelings of guilt, grief, and the desire for reparation might have contributed to a more integrative perception (whole-object) of himself and others.

This "evolution" from an immature to a mature way of dealing with emotions and reality may occur during the psychotherapeutic interaction with the therapist (transferencecounter-transference dynamics), whose observations may help the patient to understand himself and the nature of his emotional conflicts.

From a psychiatric point of view, his prodromal symptoms decreased and after 12 months of PD-P they virtually remitted, what might be associated to the development of mature aspects of his personality.

It is possible that the PD-P might also have reflected on his daily functioning (e.g., his job promotion). The observed behavioral changes suggest that Mr. A could experience the usual daily activities and social interactions not as a burden and threat, but started being able to deal with them.

During the psychotherapy process, the interaction of psychotic patients with the world, others, and themselves occur through decompensation and progressive stages, according to the model proposed by Rosenbaum and Harder ${ }^{16}$. Even though Mr. A is not psychotic (from a psychiatric point of view), he could be described as in a "decompensation stage", expressed by his attenuated psychotic symptoms and disorganized behavior. After 12 months, a more organized functioning was observed, as the patient could tolerate frustration and tension, what could be described as a "progressive stage". The SOPS outcome (Table 2) might be associated to the positive impact of PD-P.

As he learns how to deal with his internal conflicts, his anxiety diminishes and this enables him to deal with the challenges of academic and professional life. The improvement in neuropsychological functions should be analyzed carefully; first of all, his executive function improvements might have occurred due to a learning effect. Besides, it is noteworthy to mention that the improvement in attention and memory tasks might be related to the development of a mature way of dealing with emotions and reality. Most importantly, there was no worsening of his neuropsychological performance, what could indicate a higher risk to conversion to psychosis.

\section{CONCLUSION}

This case report suggests that PD-P can reduce prodromal symptoms. Nevertheless, there is a need to investigate how psychotherapies, specifically PD-P, influence neurobiology and may contribute to clinical improvement of psychiatric conditions ${ }^{17}$.

Considering the limitations of a single case report, we suggest that PD-P may be a useful tool to help UHR subjects to overcome symptoms that may act as triggers of a fullblown psychosis. A better understanding of the specificity and efficacy of PD-P as a choice of treatment for UHR individuals is needed.

\section{REFERENCES}

1. Yung AR, Nelson B. Young people at ultra high risk for psychosis: a research update. Early Interv Psychiatry. 2011;5(Suppl 1):52-7.

2. Yung AR, McGorry PD, McFarlane CA, Jackson HJ, Patton GC, Rakkar A. Monitoring and care of young people at incipient risk of psychosis. Schizophr Bull. 1996;22:283-303.

3. Hickie IB. Youth mental health: we know where we are and we can now say where we need to go next. Early Interv Psychiatry. 2011;5(Suppl 1):63-9.

4. Singh SP. Early intervention in psychosis. Br J Psychiatry. 2010;196(5):343-5. 
5. McCrone P, Craig TK, Power P, Garety PA. Cost-effectiveness of an early intervention service for people with psychosis. Br J Psychiatry. 2010;196(5):377-82.

6. Miller TJ, McGlashan TH, Rosen JL, Cadenhead K, Cannon T, Ventura J, et al. Prodromal assessment with the structured interview for prodromal syndromes and the scale of prodromal symptoms: predictive validity, interrater reliability, and training to reliability. Schizophr Bull. 2003;29(4):703-15.

7. Rietdijk J, Dragt S, Klaassen R, Ising H, Nieman D, Wunderink L, et al. A single blind randomized controlled trial of cognitive behavioural therapy in a help-seeking population with an At Risk Mental State for psychosis: the Dutch Early Detection and Intervention Evaluation (EDIE-NL) trial. Trials. 2010;11:30.

8. Morrison AP, French P, Parker S, Roberts M, Stevens H, Bentall RP, et al. Three-year followup of a randomized controlled trial of cognitive therapy for the prevention of psychosis in people at ultrahigh risk. Schizophr Bull. 2007;33(3):682-7.

9. Addington J, Epstein, Liu L, French P, Boydell KM, Zipursky RB. A randomized controlled trial of cognitive behavioral therapy for individuals at clinical high risk of psychosis. Schizophr Res. 2011;125(1):54-61.
10. Juckel G, Lempa G, Troje E. (Hg.). Psychodynamische therapie von patienten im schizophrenen Prodromalzustand. Göttingen: Vandenhoeck \& Ruprecht. 2006.

11. Leichsenring F, Rabung S. Effectiveness of long-term psychodynamic psychotherapy: a meta-analysis. JAMA. 2008;300(13):1551-65.

12. Leichsenring F, Rabung S. Long-term psychodynamic psychotherapy in complex mental disorders: update of a meta-analysis. Br J Psychiatry. 2011;199(1):15-22.

13. Uzdawinis D, Edel MA, Özgürdal S, Von Haebler D, Hauser M, Witthaus H, et al. Operationalisierte Psychodynamische Diagnostik (OPD) bei Patienten im schizophrenen Prodromalstadium - Eine explorative Studie. Z Psychosom Med Psychother. 2010;56(2):150-62.

14. Fonagy P, Luyten P. A developmental, mentalization-based approach to the understanding and treatment of borderline personality disorder. Dev Psychopathol. 2009;21(4):1355-81.

15. Segal H. Introduction to the work of Melanie Klein. London: Karnac Books; 1988.

16. Rosenbaum B, Harder S. Psychosis and the dynamics of the psychotherapy process. Int Rev Psychiatry. 2007;19 (1):13-23.

17. Cheniaux E, Zusman JA, Freitas S, Carvalho LAV, Landeira-Fernandez J. Psychoanalytic treatment: a neurobiological view. Psychol Neurosci. 2011;4(3):417-27. 